\title{
Effect of Synthesis Temperature and Alkoxy Side Chain Length on Molecular Structure and Photoelectrochemical Properties of Terthiophenes
}

\author{
Marcos J. L. Santos and Emerson M. Girotto* \\ Departamento de Química, Universidade Estadual de Maringá, Av. Colombo 5790, 87020-900 Maringá-PR, Brazil
}

As propriedades fotoeletroquímicas dos tertiofenos alcóxi substituídos poli(4,4"dimetóxi-3'metil-2,2':5',2"' tertiofeno) (PDM) e poli(4,4'”dipentóxi-3'-metil-2,2':5',2" tertiofeno) (PDP) foram investigadas em termos da influência causada pelo comprimento da cadeia lateral. Experimentos de voltametria cíclica e espectroscopia UV-Vis sugeriram que a temperatura de síntese afeta de modo diferenciado a organização molecular dos materiais e, desse modo, não deve ser usada como regra geral. A maior eficiência de conversão apresentada pelo PDM resulta de seu melhor empacotamento molecular tipo- $\pi$. Devido à sua cadeia lateral curta o PDM apresenta uma grande interação entre cadeias, a qual favorece o movimento eletrônico e a condutividade do polímero.

The photoelectrochemical properties of the alkoxy-substituted terthiophenes poly(4,4" dimethoxy3'-methyl-2,2':5',2', terthiophene) (PDM) and poly(4,4' 'dipentoxy-3'-methyl-2,2':5',2', terthiophene) (PDP) have been investigated in terms of the influence of side chain length. Cyclic voltammetry and UV-Vis experiments have suggested that the synthesis temperature affects the molecular organization in different ways and, thus it should not be used as a general rule. The more efficient light harvesting of PDM, results from its improved molecular $\pi$-stacking. Due to its short side chain, PDM presents a large chain interaction, which favors electron hopping and the polymer conductivity.

Keywords: polyterthiophene, photoelectrochemical properties, alkoxy chain length

\section{Introduction}

Since the discovery of the conductivity of organic conjugated polymers, ${ }^{1}$ a number of research groups have devoted their efforts to understanding and enhancing their properties aiming at applications in electrochemical and optical devices. ${ }^{2-6}$ In the last 15 years, the results of several studies have encouraged the investment in the field of photovoltaic and photoelectrochemical cells using organic materials..$^{7-12}$ Polythiophenes have been widely studied. This family of conductive polymer is known for its simple functionalization, $p$-type semiconductor characteristic, and relatively good stability in air in both the neutral and the oxidized states. ${ }^{13}$ However, the efficiency of photovoltaic and photoelectrochemical cells still need improving and as well as further understanding of the mechanisms around photo-driven phenomena.

The electronic and optical properties of organic conjugated polymers are controlled both by the primary

*e-mail: emgirotto@uem.br molecular structure (intramolecular functionality: $\pi$-conjugation) and by long-range organization (intermolecular interactions: $\pi$-stacking). The control of intermolecular interactions has been attained mainly through the structural, chemical, and electronic properties of side chains. ${ }^{14}$ The alkoxy substituents on the polymer chain induce a low oxidation potential, and if at the $\alpha$ position (involved in the polymerization reaction), they provide fast electropolymerization kinetics. ${ }^{15-18}$ Theoretical studies have been devoted to understanding interchain interactions and their effect on the optical properties of thiophene oligomers. ${ }^{19-23}$ The effect of both the planar and the interchain distances on the gap energy $\left(\mathrm{E}_{\text {gap }}\right)$ of oligothiophene systems are well known, and so are the effect of chain torsions on $\pi$-conjugation length. ${ }^{24}$

In all the previous cases, differences presumably due to the preparation method and conditions and the resulting structures have observed between the various materials. These differences are substantial in some cases and subtler in others. Thus, it seemed worthwhile preparing and investigating a series of conjugated systems as thoroughly 
as possible. The present contribution is one of a series of such studies.

Aiming at contributing to the understanding of how the synthesis temperature and the side chain length affect the photoelectrochemical properties of substituted terthiophenes, the present work reports some structural studies on the photoelectrochemical characterization of polymer films obtained from terthiophene derivatives ${ }^{25}$ with substituents with different lengths at positions 4,4": poly (4,4"'-dimethoxy-3'-methyl-2,2':5',2"terthiophene) and poly(4,4"-dipentoxy-3'-methyl$2,2^{\prime}: 5^{\prime}, 2^{\prime \prime}$-terthiophene). The systems were studied in solution by mono- and polychromatic irradiation. The photoelectrochemical results are discussed in terms of the possible structural organization taking into consideration the influence of the alkoxy side group and the effect of the synthesis temperature.

\section{Experimental}

The preparation procedure of monomers 4,4"dimethoxy-3'-methyl-2,2':5',2"' terthiophene DMM, and 4,4"dipentoxy-3'-methyl-2,2':5',2" terthiophene DPM (Figure 1) is reported elsewhere. ${ }^{26}$ All reagents were reagent-grade quality and used without further purification. Acetonitrile (AN Merck) was stored under argon pressure and manipulated under argon flow. Dichloromethane (DM Merck) was dehydrated with $\mathrm{CaCl}_{2}$ for $12 \mathrm{~h}$, successively distilled in the presence of $\mathrm{P}_{2} \mathrm{O}_{5}$ under argon flow, and stored in the dark under argon pressure. Tetra- $n$ butyl ammonium perchlorate (TBAP, Fluka) was purified by crystallization in methanol.

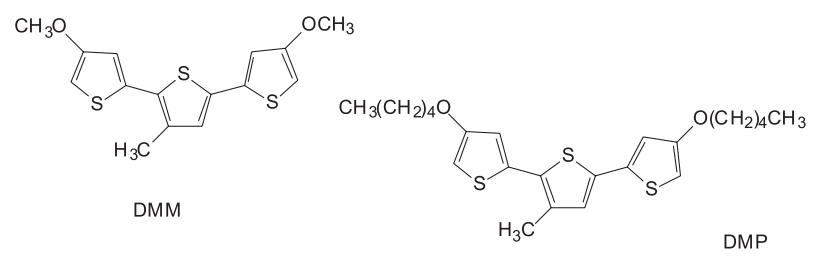

Figure 1. Structures of monomer DMM and DPM.

\section{Film preparation}

PDM and PDP films were deposited onto an ITO substrate (Delta Technologies, $20 \Omega / \mathrm{cm}^{2}$ ) and a Pt sheet by cyclic voltammetry $(\mathrm{CV})$ of $3 \mathrm{mmol} \mathrm{L}^{-1}$ of monomer in $3: 1 \mathrm{v} / \mathrm{v}$ AN/DM $+0.1 \mathrm{~mol} \mathrm{~L}^{-1}$ TBAP at controlled temperature (thermobath Tecnal TE184) at scan rate of $20 \mathrm{mV} \mathrm{s}^{-1}$. A Pt wire was used as a counter-electrode and the reference was an $\mathrm{Ag} \mid \mathrm{AgCl}$ electrode. The electrosynthesis and electrochemical characterizations were carried out with an Autolab PGSTAT 30 potentiostat/galvanostat apparatus.

\section{Spectroelectrochemical characterization}

Spectroelectrochemical measurements in the UV-Vis region were carried out using a $0.1 \mathrm{~mol} \mathrm{~L}^{-1}$ solution of $\mathrm{LiClO}_{4}$ in acetonitrile, an $\mathrm{Ag} \mid \mathrm{AgCl}$ electrode as reference, ITO-glass sheets (area of $1.0 \mathrm{~cm}^{2}$, surface resistivity $20 \Omega / \mathrm{cm}^{2}$ ) as working electrodes, and a Pt wire as a counter electrode. The in situ spectroelectrochemical measurements were carried out by placing the ITO-modified electrodes in the sample compartment of a Shimadzu spectrophotometer (UV mini 1240) and applying the potential by using an Autolab PGSTAT 30 potentiostat/ galvanostat. The absorbance spectra of the films were recorded at polarization potentials of $-0.2(v s . \mathrm{Ag} \mid \mathrm{AgCl})$.

\section{$X$-ray diffraction}

$\mathrm{X}$-ray scattering films were synthesized onto mirrorpolished Pt plates, detached from the electrodes, dried at $80{ }^{\circ} \mathrm{C}$ for $1 \mathrm{~h}$, and placed onto glass substrates for measurement. X-ray scattering was obtained in Shimadzu XD-3A model VG-108R with $\mathrm{CuK} \alpha$ radiation.

\section{Photoelectrochemical measurements}

The photoelectrochemical experiments were performed with an Autolab PGSTAT 30 potentiostat/galvanostat in a three-electrode configuration cell at room temperature. The polymers were irradiated through the ITO side (substratejelectrode interface, SE). The electrolyte was a $0.1 \mathrm{~mol} \mathrm{~L}^{-1}$ solution of $\mathrm{LiClO}_{4}$ in acetonitrile. For characterization of the photoelectrochemical cell, it was placed in a homemade optical bench consisting of a 250-W halogen lamp coupled to an AM 1.5 filter (Oriel), a monochromator (Jarrel-Ash), collimating lenses, and a water filter (Oriel). Photocurrent values under polychromatic illumination were obtained from photochronoamperometry measurements at different polarization potentials. Action spectra were obtained by normalizing the incident monochromatic light to the response of a calibrated silicon photodetector (Newport, Model 818-UV) controlled by an optical power meter (Newport, Model 1830-C). No reflection or absorption loss corrections were made.

\section{Results and Discussion}

Electrochemical deposition is a good alternative for preparing conducting polymers and it has been extensively used. ${ }^{27,28}$ One of its important advantages is the control of polymer film thickness during preparation directly through the monomer solution. It also allows improving the degree 
of polymerization by the careful selection of the synthesis temperature and the film thickness. ${ }^{29-31}$

The surface of electrosynthesized PDM and PDP films is visually homogeneous, independently of the substrate used (either Pt or ITO). The cyclic voltammograms (second cycle) acquired during the synthesis of PDM and PDP on ITO substrate at different synthesis temperatures are shown in Figure 2. An interesting behavior is observed in the reduction signals in Figure 2. The reduction curve of the film synthesized at $-10^{\circ} \mathrm{C}$ presents two cathodic peaks, hereafter referred to as peak I for the reduction process at ca. $0.40 \mathrm{~V}$ (PDM) and $0.46 \mathrm{~V}$ (PDP) and as peak II, for the reduction process at $c a .0 .05 \mathrm{~V}(\mathrm{PDM})$ and $0.10 \mathrm{~V}$ (PDP). These two reduction peaks have been earlier described by Zotti and co-workers ${ }^{32,33}$ as a result of the formation of hexameric polarons, which dimerize magnetically during polythiophene oxidation.

Upon raising the temperature to $20{ }^{\circ} \mathrm{C}$, peak I undergoes a dramatic decrease in intensity with the simultaneous increase in the intensity of peak II. The curve of the film synthesized at $30{ }^{\circ} \mathrm{C}$ presents only one peak, probably an average of peaks I and II. The reproducibility of the system was probed by triplicate experiments. Indeed, these changes were not observed in the first polymerization cycle. The wideness of the voltammetric wave suggests a certain degree of structural organization for the corresponding electroactive sites. ${ }^{15,34}$ In addition, it is observed a high concentration of long $\pi$-conjugation chains with the increase in the synthesis temperature related to the reduction process of peak II. Generally, a decrease in temperature improves the selectivity of the cation radical on the coupling site, but it also decreases the coupling reaction rate. ${ }^{15,34,35}$ Although earlier studies suggest that an increase in the synthesis temperature leads to an increase in $\pi$-conjugation length, the results presented here indicate that it cannot be established a general increasing tendency for the degree of organization in these types of systems. In fact, considering the small changes in the reduction wave observed in the second polymerization cycle (insets of Figure 2), with the increase in temperature, the level of organization of the molecular and the structural sites is only partially enhanced. This
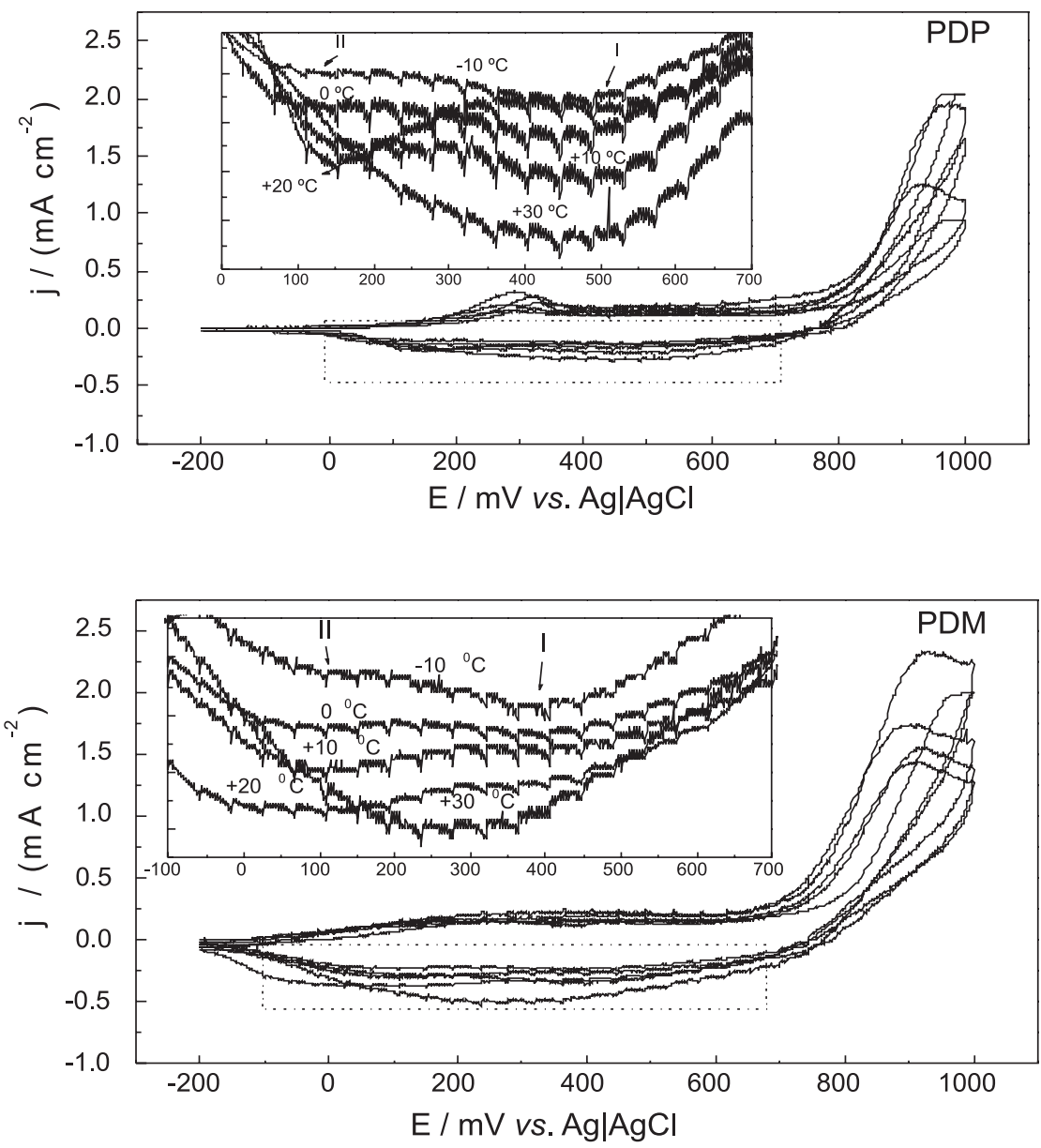

Figure 2. Voltammograms of the synthesis of PDM and PDM at $-10,0,10,20$, and $30^{\circ} \mathrm{C}$. 
organizational hypothesis derived just from voltammetric studies is not enough to elucidate the actual effect of the synthesis temperature on the structural properties of the polymers. To corroborate this hypothesis, we probed the UV-Vis absorption spectra of the PDM and PDP films. The spectra of both films present a line shape corresponding to the $\pi-\pi^{*}$ transition revealing an asymmetrical band that can be fitted by three bands. The intensity of two of the bands was observed dependent on the synthesis temperature. The results suggest that only some structures are benefited by the increase in temperature. These results corroborate the discussion on the cyclic voltammograms (Figure 2), which suggested the increase in the synthesis temperature as non-determining of the increase in the level of organization of the film. In contrast, high synthesis temperature favored the organization of polymer chains with long $\pi$-conjugation at the expenses of the short ones without shifting the maximum absorption wavelength. There seems to be a balance between the organized states of the chains with different $\pi$-conjugations.

Figure 3 shows the X-ray diffraction of the PDM and PDP films. The lowest angle signals between $\left(3^{\circ}\right.$ and $\left.5^{\circ}\right)$ of polythiophenes are usually attributed to the distance between the chains on the same plane, and the amorphoushalo signal $\left(\mathrm{ca} .25^{\circ}\right)$ is attributed to the distance between
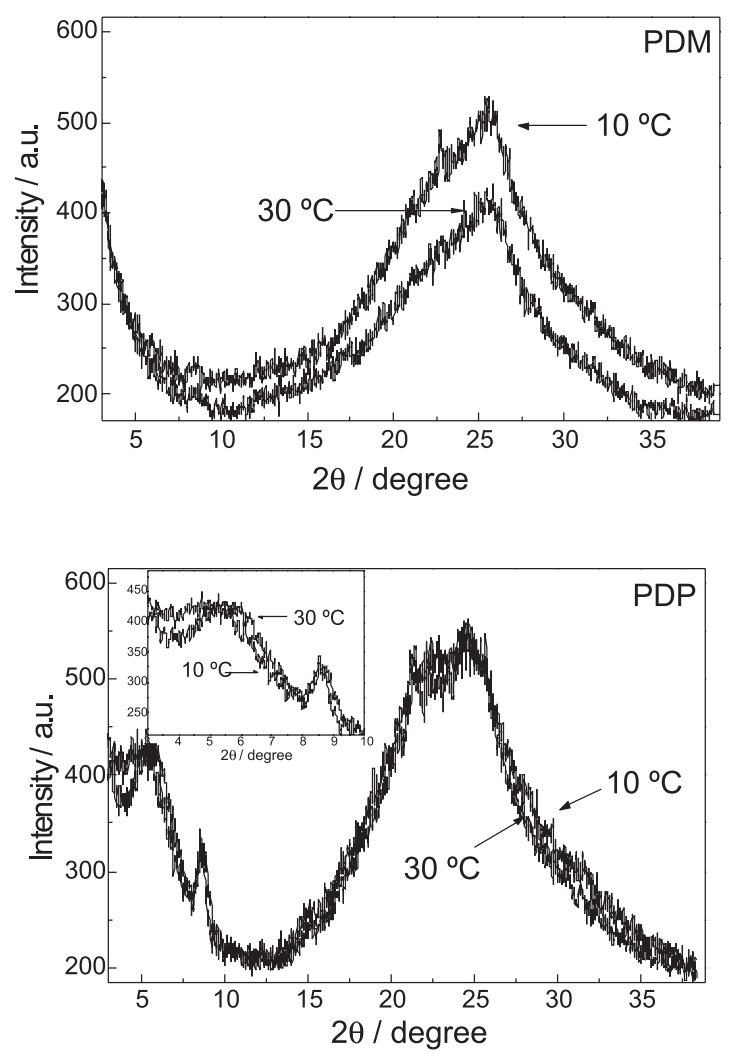

Figure 3. X-ray diffraction patterns of PDM and PDP at 10 and $30{ }^{\circ} \mathrm{C}$ deposited on platinum. different planes with interfaced aromatic rings. ${ }^{36,37}$ The amorphous-halo signal at $c a .25^{\circ}$ observed for both PDM and PDP corresponds to the $\pi$-stacking distance, $3.6 \AA$, which is similar to that of poly(3-hexylthiophene), $3.8 \AA^{38}$ The sharper peak of PDM suggests that it has a higher molecular organization than that of PDP. Indeed, the X-ray diffractogram of PDP shows a broader halo with maximum at $c a .25^{\circ}$ and a strong shoulder at $c a .20^{\circ}$ suggestive of the interference of the long side chain in the interaction of the backbones, which leads some chains to be farther apart, $4.5 \AA{ }^{38}$ The closer $\pi$-stacking of PDM is also observed in the absorption spectrum, where a shoulder at $c a .650 \mathrm{~nm}$ is attributed to interchain contributions to the UV-Vis spectrum of PDM. ${ }^{39}$ The UV-Vis spectrum of PDP does not display the shoulder on the long wavelength side of the absorption maximum, (spectrum not shown). The lowest angle signal at $2 \theta=5.5^{\circ}$ of the PDP film synthesized at $30^{\circ} \mathrm{C}$ is narrower than the signal at $2 \theta=5.0^{\circ}$ of the film synthesized at $10^{\circ} \mathrm{C}$. The signals at the lowest angle are more evident in polymers with long side chains, such as the pentoxy group of PDP, ${ }^{40,41}$ which explains why this signal was not observed for PDM.

Figure 4 shows the photocurrent of PDM and PDP films synthesized at 10 and $30^{\circ} \mathrm{C}$ under polychromatic irradiation and open-circuit conditions, respectively, with different thicknesses, as a function of the applied potential. The comparison of Figures 4 clearly shows significant differences in the energy conversions of the synthesized films with different thicknesses, temperatures, and monomer structures. Figure 4 displays the distinct optimum synthesis temperatures of the polymers. PDM synthesized at $10^{\circ} \mathrm{C}$ presents more efficient light harvesting than that of PDM synthesized at $30^{\circ} \mathrm{C}$ for all film thicknesses studied in this work. In contrast, the PDP films synthesized at $30^{\circ} \mathrm{C}$ presented more efficient light harvesting than those of all PDP films synthesized at $10^{\circ} \mathrm{C}$. Due to the different alkoxy chain lengths, the polymers presented distinct optimum synthesis temperatures, being higher for PDP than for PDM. During the synthesis, the monomers and the oligomers bind to form the polymer; this reaction must overcome the activation energy, which involves reactivity and steric hindrance, among other effects. The pentoxy groups have a larger volume than those of the methoxy groups, thus they also present higher steric hindrance to the coupling sites during the polymerization process. Thus, PDP requires more energy to overcome the synthesis steric hindrance and a higher synthesis temperature. When enough energy is supplied, the monomeric coupling leading to the formation of the polymer is allowed and it is obtained a polymer with longer conjugation length and better optical and photoelectrochemical properties. In addition, it is observed 

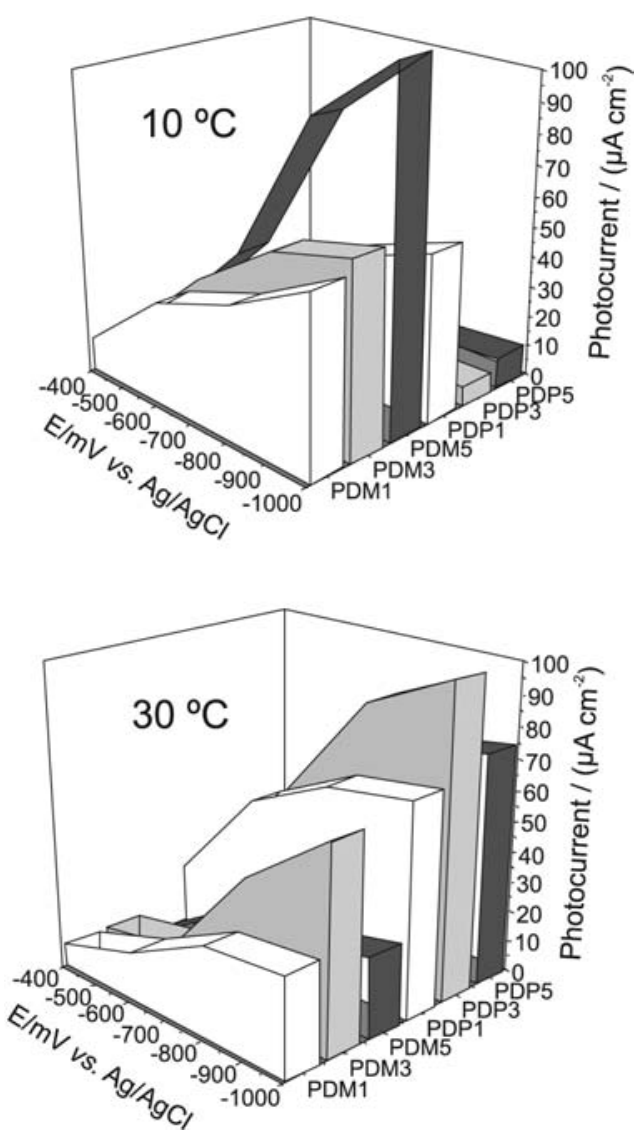

Figure 4. Photocurrent densities under polychromatic irradiation recorded during chronoamperometry of PDM and PDP films synthesized at 10 and $30{ }^{\circ} \mathrm{C}$ deposited on ITO. Thicknesses of the measured films: PDM1 and PDP1, $200 \mu \mathrm{m}, \mathrm{PDM} 3$ and PDP3, $300 \mu \mathrm{m}, \mathrm{PDM} 5$ and PDP5, $400 \mu \mathrm{m}$. Electrolyte: $\mathrm{LiClO}_{4} 0.1 \mathrm{~mol} \mathrm{~L}^{-1}$, acetonitrile, redox couple $\mathrm{O}_{2} / \mathrm{O}_{2}^{-}$.

an increase in light harvesting towards the more neutral state. Due to the generation of intermediate energy levels, one could expect more efficient light harvesting from the films in oxidized states with the decrease in the energy gap, which would favor the photoexcitation of electrons to the conduction band. However, recombination processes play a very important role in the efficiency of photoconductivity. In these films, the electrons and holes go through the same path; therefore, the bimolecular recombination rate is high. During the oxidation of the polymer, the increase in the density of intermediate states of energy favors the electron-hole pair recombination. The large density of the charge carriers due to the small energy differences favors the monomolecular recombination. ${ }^{42}$

Figure 5 shows the IPCE measurement results of PDM and PDP films synthesized at optimum synthesis temperatures, $10{ }^{\circ} \mathrm{C}$ and $30^{\circ} \mathrm{C}$, respectively, calculated from short-circuit photocurrent spectra using light intensity measurement calibrated with a photodiode for each wavelength. The polymers are in their neutral states $(-0.9 \mathrm{~V})$, in which they behave as p-type semiconductors.

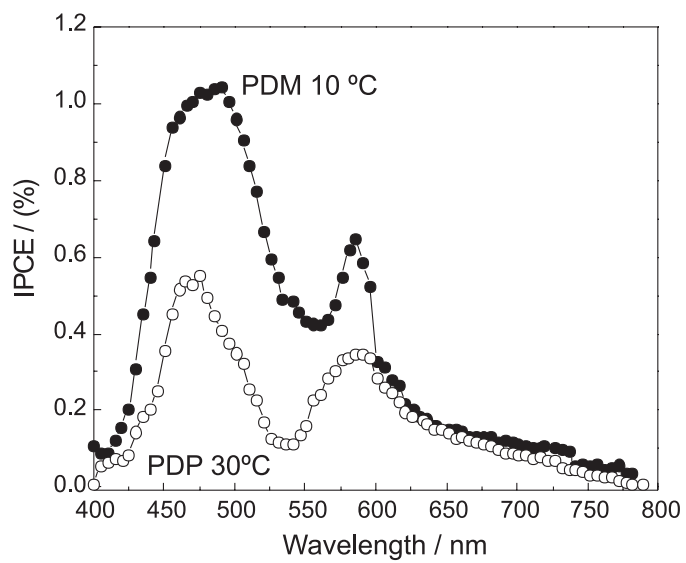

Figure 5. IPCE curves of PDM and PDP films synthesized at 10 and $30{ }^{\circ} \mathrm{C}$, respectively. Electrolyte: $\mathrm{LiClO}_{4} 0.1 \mathrm{~mol} \mathrm{~L}^{-1}$, acetonitrile, redox couple $\mathrm{O}_{2} / \mathrm{O}_{2}^{-}$.

The absorptions of PDM and PDP are in about the same spectral region; however, PDM presents higher photocurrent values than PDP does. As mentioned, the electrochemical and spectroelectrochemical properties of polyterthiophenes are dependent on the side group length, which leads to changes in their absorption spectra and redox properties. ${ }^{26}$ Larger intermolecular interactions provide smaller energy gap transitions and increases light harvesting. ${ }^{43,44}$ However, in our case, PDM does not present a smaller $\mathrm{E}_{\text {gap }}$, ${ }^{22}$ despite its larger light harvesting. To explain this phenomenon, we suggest the existence of other effects like molecular ordering regarding micro-conformations (local conformations). Due to the low rotational barrier of the methoxy group, the PDM molecules can quickly achieve many different molecular conformations (lattice ordering) and provide a dynamically flexible material. The different rotational barriers due to the different alkoxy chain lengths of the methoxy and pentoxy groups promote different molecular conformations. This larger possibility of molecular conformation favors the packing of the chains and their more intense interaction. According to the literature, a more effective interaction between the chains leads to a polymer with better photoconductive properties, since conduction occurs by hopping and it is easier in a more densely packed system. ${ }^{45,46}$ The X-ray diffractograms (Figure 3) show a closer $\pi$-stacking for PDM, and considering that the rate of recombination is controlled by carrier hopping, in a more densely packed system such as PDM, a lower recombination rate would lead to higher photocurrent.

In addition, as alkoxy groups are good electron donors, a higher stability of PDP during the polymerization process would be expected, compared to that of PDM, leading to a larger conjugation length. The stabilization results from the 
interaction of electrons in sigma bond (usually either $\mathrm{C}-\mathrm{H}$ or C-C) with an adjacent empty (or partially filled) antibonding p-orbital to give an extended molecular orbital.

\section{Conclusions}

Due to the different chain lengths of the side groups, PDM and PDP, both polyterthiophenes, present different photoelectrochemical properties. The alkoxy groups (methoxy and pentoxy) work as electron donor sites, stabilizing the positive sites generated during the oxidative polymerization by hyperconjugative effect. This stabilization is desirable, as it leads to the formation of polymers with a long $\pi$-conjugation. Also due to the more intense steric hindrance effect of the pentoxy groups, the PDM molecules can quickly achieve many different molecular conformations. The more organized PDM system has enhanced photoelectrochemical properties and larger light harvesting.

\section{Acknowledgments}

The financial support of Fundação Araucária (contract no. 2562), CNPq (PROFIX project No. 541058/01-0) and CAPES Brazilian agencies are gratefully acknowledged. We also thank C. Bertarelli (Politecnico di Milano, Italy) for monomer supply.

\section{References}

1. Shirakawa, H., Louis, E. J.; MacDiarmid, A.G.; Chiang, C. K.; Heeger, A. J.; J. Chem. Soc., Chem. Commun. 1977, 16, 578.

2. Skotheim, T. A.; Handbook of Conducting Polymers, Marcel Dekker: New York, 1986.

3. Tang, C. W.; Appl. Phys. Lett. 1986, 48, 183.

4. Wöhrle, D.; Meissner, D.; Adv. Mater. 1991, 3, 129.

5. Yu, G.; Gao, J.; Hummelen, J. C.; Wudl, F.; Heeger, A. J.; Science 1995, 270, 1789.

6. Granström, M.; Petritsch, K.; Arias, A. C.; Lux, A.; Anderson, M. R.; Friend, R.H.; Nature 1998, 395, 257.

7. Winder, C.; Sariciftci, N. S.; J. Mater. Chem. 2004, 14, 1077.

8. Shaheen, S. E.; Radspinner, R.; Peyghambarian, N.; Jabbour, G. E.; Appl. Phys. Lett. 2001, 79, 2996.

9. Shaheen, S. E.; Brabec, C. J.; Sariciftci, N. S.; Padinger, F.; Fromherz, T.; Hummelen, J. C.; Appl. Phys. Lett. 2001, 78, 841.

10. Shaheen, S. E.; Radspinner, R.; Peyghambarian, N.; Jabbour, G. E.; Appl. Phys. Lett. 2001, 79, 2996.

11. Schön, J. H.; Kloc, C.; Bucher, E.; Batlogg, B.; Nature 2000, 403, 408.

12. Peumans, P.; Uchida, S.; Forrest, S. R.; Nature 2003, 425, 128.

13. Roncali, J.; Chem. Rev. 1992, 92, 711.
14. Egbe, D. A. M.; Carbonnier, B.; Ding, L.; Mühlbacher, D.; Birckner, E.; Pakula, T.; Karasz, F. E.; Grummt, U.-W.; Macromolecules 2005, 15, 6269.

15. Girotto, E. M., Casalbore-Miceli, G.; Camaioni, N.; De Paoli, M.-A.; Fichera, A. M.; Belobrzeckaja, L.; Gallazzi, M. C.; J. Mater. Chem. 2001, 11, 1072.

16. Dini, D.; Decker, F.; Zotti, G.; Synth. Met. 1999, 101, 22.

17. Scherzer, T.; Decker, U.; Polymer 2000, 41, 7681.

18. Dini, D.; Decker, F.; Zotti, G.; Schiavon, G.; Zecchin, S.; Andreani, F.; Salatelli, E.; Lanzi, M.; Electrochim. Acta 1999, 44, 1911.

19. Bredas, J. L.; Cornil, J.; Beljonne, D.; Santos, D. A.; Shuai, Z.; Acc. Chem. Res. 1999, 32, 267.

20. Beljonne, D.; Cornil, J.; Silbey, R.; Millie, P.; Bredas, J. L.; J. Chem. Phys. 2000, 111, 4749.

21. Cornil, J.; Beljone, D.; Santos, D. A.; Calbert, J. P.; Shuai, Z.; Bredas, J. L.; Org. Electrolumin. 2000, 4, 403.

22. Santos, M. J. L.; Rubira, A. F.; Pontes, R. M.; Basso, E. A.; Girotto, E. M.; J. Solid State Electrochem. 2006, 10, 117.

23. Cornil, J.; Calbert, J. P.; Beljonne, D.; Silbey, R.; Bredas, J. L.; Synth. Met. 2001, 119, 1.

24. Zhang, G.; Pei, Y.; Ma, J.; Yin, K.; J. Phys. Chem. B 2004, 108, 6988.

25. Dini, D.; Decker, F.; Zotti G.; Schiavon, G.; Zecchin, S.; Andreani, F.; Salatelli, E.; Chem. Mater. 1999, 11, 3484.

26. Casalbore-Miceli, G.; Camaioni, N.; Gallazzi, M. C.; Albertin, L.; Fichera, A. M.; Geri, A.; Girotto, E. M.; Synth. Met. 2002, $125,307$.

27. Doblhofer, K.; Rajeshwar, K. In Handbook of Conducting Polymers; Skotheim, T. A.; Elsenbaumer, R. L.; Reynolds, J. R., eds.; Marcel Dekker: New York, 1998, ch. 20.

28. Zotti, G. In Handbook of Organic Conductive Molecules and Polymers; Nalwa, H. S., ed.; Wiley: New York, 1997, Vol. 2, ch. 4.

29. Camaioni, N.; Casalbore-Micelli, G.; Beggiato, G.; Cristani, M.; Summonte, C.; Thin Solid Films 2000, 366, 211.

30. Zhao, C.; Wang, H.; Jiang, Z.; Appl. Surf. Sci. 2003, 207, 6.

31. Tsekouras, G.; Too, C. O.; Wallace, G. G.; Electrochim. Acta 2005, 50, 3224.

32. Zotti, G.; Schiavon, G.; Berlin, A.; Pagani, G.; Chem. Mater. 1993, 5,620 .

33. Zotti, G.; Schiavon, G.; Comisso, N.; Electrochim. Acta 1990, 35,1815

34. Girotto, E. M.; Camaioni, N.; Casalbore-Miceli, G.; De Paoli, M.-A.; Fichera, A. M.; Gallazzi, M. C.; J. Appl. Electrochem. 2001, 31, 335 .

35. Casalbore-Miceli, G.; Camaioni, N.; Fattori, V.; Fichera, A. M.; Gallazzi, M. C.; Geri, A.; Girotto, E. M.; Giro, G.; Synth. Met. 2001, 121, 1575 .

36. Davidson, R. G.; Hammond, L. C.; Turner, T. G.; Wilson, A. R.; Synth. Met. 1996, 81, 1. 
37. Mitchell, G. R.; Geri, A.; J. Phys. D.: Appl. Phys. 1987, 20, 1346.

38. Bao, Z.; Lovinger, A. J.; Cherniavskaya, O.; Macromol. Symp. 2000, 154, 199.

39. Brown, P. J.; Phys. Rev. B: Condens. Matter Mater. Phys. 2003, 67, 64203

40. Mardalen, J.; Fell, H. J.; Samuelsen, E. J.; Bakken, P. H. J.; Carlsen, M. R.; Macromol. Chem. Phys. 1995, 196, 553.

41. Winokur, M. J. In Handbook of Conducting Polymers; Skotheim, T. A.; Elsenbaumer, R. L.; Reynolds, J. R., eds.; Marcel Dekker: New York, 1998, ch. 25.

42. Arkhipov, V. I.; Adriaensses, G. J.; J. Phys.: Condens. Matter 1997, 9, 6869.
43. Clarke, T. M.; Gordon, K. C.; Officer, D. L.; Hall, S. B.; Collis, G. E.; Burrell, A. K.; J. Phys. Chem. A 2003, 107, 11505.

44. Barta, P.; Osikowicz, W.; Salaneck, W. R.; Zgorska, M.; Niziol, S.; Synth. Met. 1999, 101, 295.

45. Laquai, F.; Wegner, G.; Bassler, H.; Philos. Trans. R. Soc. London, Ser. A 2007, 365, 1473.

46. Arkhipov, V. I.; Emelianova, E. V.; Bassler, H.; Philos. Mag. B 2001, 81, 985.

Received: May 21, 2008 Web Release Date: December 4, 2008 